University of Wollongong

Research Online

Faculty of Engineering and Information

Faculty of Engineering and Information

Sciences - Papers: Part A

Sciences

$1-1-2014$

Effects of hypochlorite exposure on morphology and trace organic contaminant rejection by NF/RO membranes

Alexander R. Simon

University of Wollongong, asimon@uow.edu.au

Long D. Nghiem

University of Wollongong, longn@uow.edu.au

Follow this and additional works at: https://ro.uow.edu.au/eispapers

Part of the Engineering Commons, and the Science and Technology Studies Commons

Research Online is the open access institutional repository for the University of Wollongong. For further information contact the UOW Library: research-pubs@uow.edu.au 


\title{
Effects of hypochlorite exposure on morphology and trace organic contaminant rejection by NF/RO membranes
}

\author{
Abstract \\ The impacts of membrane degradation due to chlorine attack on the rejection of inorganic salts and trace \\ organic contaminants by nanofiltration (NF) and reverse osmosis (RO) membranes were investigated in \\ this study. The rejection of trace contaminants was examined at environmentally relevant concentrations. \\ Changes in the membrane surface morphology were observed as a result of chlorine exposure. A small \\ increase in rejection was consistently observed with all four membranes selected in this study after being \\ exposed to a low concentration of hypochlorite $(100 \mathrm{ppm})$. In contrast, a higher concentration of \\ hypochlorite (i.e., 2000 ppm) could be detrimental to the membrane separation capacity. Membranes with \\ severe chlorine impact showed a considerable decrease in rejection over filtration time, possibly due to \\ rearrangement of the polyamide chains under the influence of chlorine degradation and filtration \\ pressure. The reported results indicate that loose NF membranes are more sensitive to chlorine exposure \\ than RO membranes. The impact of hypochlorite exposure (both positive and negative) on rejection is \\ dependent on the strength of the hypochlorite solution and is more significant for the neutral \\ carbamazepine compound than the negatively charged sulfamethoxazole.

\section{Disciplines} \\ Engineering | Science and Technology Studies

\section{Publication Details} \\ Simon, A. \& Nghiem, L. D. (2014). Effects of hypochlorite exposure on morphology and trace organic \\ contaminant rejection by NF/RO membranes. Membrane Water Treatment, 5 (4), 235-250.
}




\title{
Effects of hypochlorite exposure on morphology and trace organic contaminant rejection by NF/RO membranes
}

\author{
Alexander Simon and Long D. Nghiem ${ }^{*}$ \\ School of Civil Mining and Environmental Engineering \\ The University of Wollongong, Wollongong, NSW 2522, Australia \\ (Received , Revised , Accepted )
}

\begin{abstract}
The impacts of membrane degradation due to chlorine attack on the rejection of inorganic salts and trace organic contaminants by nanofiltration (NF) and reverse osmosis (RO) membranes were investigated in this study. The rejection of trace contaminants was examined at environmentally relevant concentrations. Changes in the membrane surface morphology were observed as a result of chlorine exposure. A small increase in rejection was consistently observed with all four membranes selected in this study after being exposed to a low concentration of hypochlorite $(100 \mathrm{ppm})$. In contrast, a higher concentration of hypochlorite (i.e.: 2000 ppm) could be detrimental to the membrane separation capacity. Membranes with severe chlorine impact showed a considerable decrease in rejection over filtration time, possibly due to rearrangement of the polyamide chains under the influence of chlorine degradation and filtration pressure. The reported results indicate that loose NF membranes are more sensitive to chlorine exposure than RO membranes. The impact of hypochlorite exposure (both positive and negative) on rejection is dependent on the strength of the hypochlorite solution and is more significant for the neutral carbamazepine compound than the negatively charged sulfamethoxazole.
\end{abstract}

Keywords: Nanofiltration, reverse osmosis, water recycling, hypochlorite, membrane degradation, trace organic contaminants.

* Corresponding author: Long Duc Nghiem, Email: longn@uow.edu.au; Ph +61 242214590 


\section{Introduction}

Potable water scarcity presents a major challenge to water authorities in many regions in the world particularly in the context of on-going climate change and continuing population growth (Shannon et al., 2008). A strategic approach to address this issue is the augmentation of the natural water supply with reclaimed water from treated effluent using advanced water treatment technologies including high-pressure membrane processes such as reverse osmosis (RO) and nanofiltration (NF) (Fujioka et al., 2012; Wintgens et al., 2005). Most commercially available NF and RO membranes for water treatment are polyamide thin-film composite (TFC) and consist of a thin polyamide active skin layer that is responsible for solute separation on top of a porous supporting layer (Chang et al., 2010). Polyamide membranes offer excellent permeate flux, high salt and trace organic rejection, durability and a wide operating $\mathrm{pH}$ range, however, they are susceptible to chlorine degradation. This particular drawback of polyamide membranes has an important implication when water recycling applications are involved (Van der Bruggen et al., 2008). Due to a moderate organic content and the high biofouling potential of secondary treated effluent, chlorine (typically in the form of hypochlorite solution) or monochloramine residuals are used to suppress biological growth in the feed water. Although the feed water is usually dechlorinated prior to NF/RO filtration, membrane exposure to low concentrations of chlorine is an inevitable outcome (Glater et al., 1994; Soice et al., 2004). In fact, it is not uncommon for full-scale NF and RO installations to use feed water with up to $6 \mathrm{mg} \mathrm{L}^{-1}$ of total chlorine in the form of chloramines (Bartels et al., 2005; Wilf and Alt, 2000) despite the recommended free chlorine tolerance of less than $0.1 \mathrm{mg} \mathrm{L}^{-1}$ by most membrane manufacturers. Due to chlorine exposure, certain structural changes within the polyamide skin layer occur and can ultimately lead to a compromised membrane performance as often described by an enhanced salt passage (Glater et al., 1994; Kang et al., 2007b; Kwon et al., 2006). Chlorine attack may lead to conformational rearrangement in the polyamide matrix or even cleavage of the polyamide linkage (Glater et al., 1994; Soice et al., 2004; Soice et al., 2003). While chlorine attack has been recognized as an important issue for polyamide membranes for many years, the exact chemical mechanism of chlorine-polymer interaction and its subsequent impact on solute separation is not yet fully understood (Glater et al., 1994; Soice et al., 2003). More importantly, studies available to date have focused almost exclusively on the passage of inorganic salts as a direct consequence of membrane degradation due to chlorine attack (da Silva et al., 2006; Kang et al., 2007b; Kwon et al., 2006). The effects chlorine attack on the rejection of trace organic chemicals remain poorly understood (Urase and Sato, 2007). 
The removal mechanisms of trace contaminants are quite complex and can be governed by many factors such as membrane characteristics, physicochemical properties of the solutes, and solution chemistry. Separation behaviours of some trace organic contaminants can be quite different from those of inorganic salts (Bellona and Drewes, 2005; Bellona et al., 2004; López-Muñoz et al., 2009; Nghiem et al., 2006; Nghiem et al., 2004; Van der Bruggen et al., 2006). By altering the membrane surface characteristics, membrane fouling can exert a considerable impact on the removal of trace organic contaminants by NF/RO membranes (Agenson and Urase, 2007; Nghiem and Coleman, 2008; Nghiem et al., 2008a; Nghiem et al., 2008b; Verliefde et al., 2009; Xu et al., 2006). Similarly, it is likely that changes in the membrane characteristics due to prolonged exposure to low concentration of chlorine or accidental exposure to an elevated concentration of chlorine can significantly alter the separation process of trace contaminants by NF and RO membranes.

The aim of this study was to elucidate the effects of hypochlorite exposure on membrane surface properties and the subsequent rejection of selected trace contaminants by commercially available NF and RO membranes. Changes in the membrane surface properties were systematically characterized using scanning-electron microscopy - energy dispersive spectrometry (SEM-EDS), contact angle measurement, Fourier transform infrared spectroscopy (FTIR) and atomic force microscopy analysis (AFM). The effects of membrane degradation on the separation process were elucidated by comparing the membrane rejection of inorganic salts and trace contaminants by virgin and hypochlorite treated membranes. Furthermore, changes in the rejection of salt and trace contaminants were related to the modifications in the membrane properties.

\section{Materials and methods}

\subsection{Selected membranes}

Two nanofiltration (NF270 and NF90) and two reverse osmosis (ESPA2 and BW30) membranes were used in this study. These are commercially available and have been widely used in water recycling and potable water treatment applications, particularly to reduce salinity and for the removal of trace organic contaminants. The NF270, NF90 and BW30 were supplied by Dow Chemical (Minneapolis, MN) and were stored dry. The ESPA2 membrane was supplied by Hydranautics (Oceanside, CA) and was stored wet in Milli-Q water at $4{ }^{\circ} \mathrm{C}$. 


\subsection{Sodium hypochlorite exposure}

The sodium hypochlorite $(\mathrm{NaOCl})$ used in this study was of commercial grade with an active content of $4.2 \%$ (wt/wt). Membrane exposure to $\mathrm{NaOCl}$ was simulated by immersing the membrane samples in a sealed bath of $\mathrm{NaOCl}$ over 18 hours at $\mathrm{pH} 7$ and room temperature (20 $\left.{ }^{\circ} \mathrm{C}\right)$. Three concentrations of $\mathrm{NaOCl}\left(100,500\right.$ and 2,000 $\left.\mathrm{mg} \mathrm{L}^{-1}\right)$ were used to induce an accelerated chlorine exposure effect. These concentrations were denoted as D100, D500, and D2000, respectively. The $\mathrm{pH}$ of each chlorine solution was adjusted with analytical grade $\mathrm{HCl}$. After exposure, the membranes were rinsed gently with Milli-Q water and stored wet in a closed container at $4{ }^{\circ} \mathrm{C}$. Prior to any filtration and surface integrity test, the virgin membrane samples were rinsed gently with Milli-Q water to remove any protection layer.

\subsection{Membrane characterisation}

\subsubsection{Contact angle measurement}

Contact angle measurement of the virgin and hypochlorite exposed membranes was performed with a Rame-Hart Goniometer (Model 250, Rame-Hart, Netcong, NJ) using the standard sessile drop method. Milli-Q water was used as the reference solvent. The membranes were air dried prior to the measurement. At least 5 droplets were applied onto duplicate membrane samples and contact angle was measured on both sides of the droplet.

\subsubsection{Membrane chemistry}

Fourier transform infrared spectroscopy (FTIR) measurement was performed with an IRAffinity-1 instrument (Shimadzu, Kyoto, Japan) equipped with a diamond crystal. The air-dried membrane samples were pressed firmly against the crystal and the measured spectrum was between $750 \mathrm{~cm}^{-1}$ and $1750 \mathrm{~cm}^{-1}$. Each scan was performed 20 times at a resolution of $1 \mathrm{~cm}^{-1}$.

\subsubsection{Atomic force microscopy}

Surface morphology of the air dried membrane was analysed using a multimode atomic force microscope (AFM 3100, Digital Instruments, Santa Barbara, CA) in air in tapping mode operation using an oxide sharpened SiN probe. The membrane surface roughness was measured in replicate over an area of $1 \mu \mathrm{m} \times 1 \mu \mathrm{m}$. In this study, root mean square of the membrane topographic features within the measured area of $1 \mu \mathrm{m} \times 1 \mu \mathrm{m}$ was defined as surface roughness. 


\subsubsection{Scanning electron microscopy with energy dispersive spectrometry}

Scanning-electron microscopy (SEM) analysis was conducted using a JSM-6490LA (JOEL Japan) system, which was equipped with an integrated energy dispersive spectrometer (EDS). EDS analysis of all membrane samples was taken at 3,000 times magnification, apply voltage of $15 \mathrm{kV}$, spot size of $65 \mathrm{~nm}$ for 60 seconds.

\subsection{Filtration setup and protocol}

A laboratory-scale cross-flow NF/RO filtration rig was used in this study. This NF/RO filtration rig has been described in details elsewhere (Simon et al., 2013). Briefly, this set-up consisted of a stainless steel plate-and-frame membrane cell with an effective surface area of $40 \mathrm{~cm}^{2}(4 \mathrm{~cm} \times 10$ $\mathrm{cm}$ ), a stainless steel feed reservoir, and a high-pressure pump (Hydra-cell, Wanner Engineering Inc. Minneapolis, MN, USA). The concentrate and permeate flow rate was monitored by a rotameter (MPB Industries, Tonbridge, Kent, UK) and a digital flowmeter (GJC Instruments Ltd., UK), which was connected to a personal computer. Feed pressure and cross-flow velocity were controlled by means of a by-pass valve and a back-pressure regulator.

In preparation for each experiment, the membrane was stabilized at 18 bar using Milli-Q water until the permeate flux attained a constant value. The Milli-Q water used for stabilizing was exchanged with 10 litres of an electrolyte solution containing $1 \mathrm{mM} \mathrm{CaCl}_{2}, 20 \mathrm{mM} \mathrm{NaCl}$ and 1 $\mathrm{mM} \mathrm{NaHCO} 3$ at $\mathrm{pH}$ 8. The feed reservoir temperature was kept at $20 \pm 0.1{ }^{\circ} \mathrm{C}$ by a PID control refrigerator (Neslab RTE7, Thermo Fisher Scientific, Canada) throughout the experiment. After membrane compaction, sulfamethoxazole and carbamazepine were spiked into the feed reservoir to a concentration of $750 \mathrm{ng} / \mathrm{L}$ each. Unless otherwise stated, both the concentrate and permeate were recycled back to the feed reservoir. Feed and permeate samples of $500 \mathrm{~mL}$ each were collected after 25 hours since the spiking of the trace organic contaminants. The samples were extracted immediately using Oasis HLB solid-phase extraction (SPE) cartridges (Waters Corporation, Millford, MA). The SPE cartridges were completely dried by ultra pure nitrogen gas and were stored in a freezer at $-18^{\circ} \mathrm{C}$.

\subsection{Trace organic contaminant analysis}

Sulfamethoxazole and carbamazepine were selected for investigation to simulate a negatively charged and a neutral trace organic compound, respectively. They have been frequently detected in secondary treated effluent and sewage impacted water bodies at concentrations of up to several hundred nanograms per litre (ng/L). Their key physicochemical properties are shown in Table 1. 
The selected trace contaminants were of analytical grade and were purchased from Sigma-Aldrich (Saint Louis, MO, USA). Trace organic analysis were then conducted using an Agilent 1200 high pressure liquid chromatography (HPLC) coupled with an Applied Biosystems API 4000 Q-Trap triple-quadrupole mass spectrometer. Observed retention is defined as $R=100 \times\left(1-C_{\mathrm{P}} / C_{\mathrm{F}}\right)$, where $C_{\mathrm{P}}$ and $C_{\mathrm{F}}$ are the permeate and the feed concentrations, respectively.

\section{[TABLE 1]}

\section{Results and discussion}

\subsection{General membrane properties}

Water permeability of the NF and RO polyamide membranes varies greatly, ranging from $12.2 \mathrm{~L}$ $\mathrm{m}^{2} \mathrm{~h}^{-1}$ bar $^{-1}$ for the loose NF270 to as low as $2.9 \mathrm{~L} \mathrm{~m}^{2} \mathrm{~h}^{-1}$ bar $^{-1}$ for the reverse osmosis membrane BW30 (Table 2). The NF270 has a unique set of membrane properties. While the active skin layer of all other membranes is made of fully aromatic polyamide, NF270 membrane has a semiaromatic piperazine-based polyamide active skin layer. According to the manufacturer, the NF270 was designed for high organic and colour removal with very high $\mathrm{NaCl}$ salt passage. In contrast, the NF90 and the two RO membranes BW30 and ESPA2 can achieve near complete rejection of $\mathrm{NaCl}$ (Table 2). It is interesting to note that while SEM analysis can provide clear surface images of the NF90, ESPA2 and BW30 membranes, no clear topographic feature of the NF270 can be observed at 30,000 magnifications (Figure 1). This is also consistent with the fact that the NF270 has a very smooth surface (average surface roughness of less than $10 \mathrm{~nm}$ ) as described below. According to the manufacturer, the free chlorine tolerance for all four membranes is less than 0.1 $\mathrm{mg} \mathrm{L}^{-1}$.

\section{[TABLE 2]}

\section{[FIGURE 1]}

\subsection{Impact of chlorine on membrane surface properties}

\subsubsection{Scanning electron microscopy with energy dispersive spectrometry}

Effects of chlorine exposure on the membrane surface morphology were examined by comparing properties of the virgin membranes and of membrane samples after being exposed to a hypochlorite solution. While no chlorine peak was detected from virgin membrane samples by scanning electron microscopy - energy dispersive spectroscopy (SEM - EDS) analysis, traces of chlorine were consistently observed with all membrane samples that have been exposed to hypochlorite (data not shown). It is noted that after hypochlorite treatment, the membranes were 
rinsed thoroughly to remove any hypochlorite residual on the membrane surface. Using X-ray photoelectron spectroscopy, Kwon and Leckie (Kwon and Leckie, 2006) have also reported chlorine uptake to the membrane polymeric matrix after being exposed to a hypochlorite solution. Chlorination of the polyamide polymer can occur through the exchange of the hydrogen in the amine group $(\mathrm{N}-\mathrm{H})$ with chlorine to a non-amine group $(\mathrm{N}-\mathrm{Cl})$. This can happen because the amino group is vulnerable to electron withdrawing effects of the carbonyl group (Glater et al., 1994). Chlorine can also directly attack the aromatic ring via electrophilic aromatic substitution. Ring-chlorination can also occur when molecular chlorine is released from the previously chlorinated amine groups $(\mathrm{N}-\mathrm{Cl})$ due to intermolecular rearrangement forming various aromatic substitution products. The molecular chlorine is highly aggressive and can rapidly attack aromatic rings via electrophilic substitution. This reaction is called Orton-rearrangement and has been reported to be time dependent (Glater et al., 1994). Ring-chlorination can be very detrimental to fully aromatic polyamide membranes. However, there is little evidence that ring-chlorination can actually occur at a low free chlorine concentration. It has been further reported that it is possible to reverse the $\mathrm{N}$-chlorination by treating the membranes with an alkaline solution while ringchlorination stays irreversible (Glater et al., 1994), which can be detected by (SEM - EDS).

\subsubsection{Fourier transform infrared spectroscopy}

The impact of chlorine exposure on polyamide membranes can be also seen by FTIR analysis (Figure 2). A detailed identification of all peaks that can be found in the examined range of 600 to $1,750 \mathrm{~cm}^{-1}$ can be found in Table 3. It is noteworthy that the penetration depth of FTIR depends on the wavelength and ranges from a few hundred nanometres to a few micrometers, whereas, the active-top layer of TFC membranes is usually significant thinner (Freger et al., 2002; Semião and Schäfer, 2013). In fact, because the NF270 membrane has an ultra-thin skin layer (ca. $20 \mathrm{~nm}$ ) (Freger et al., 2002; Semião and Schäfer, 2013), no chlorination of the skin layer can be found on this membrane. By contrast, due to the thicker active membrane skin layer of the BW30, NF90 and ESPA2, the impact of membrane chlorination can be clearly seen at FTIR bands of 1,667 and $1,542 \mathrm{~cm}^{-1}$, which represent $\mathrm{C}=\mathrm{H}$ (Amide-II band) and N-H (Amide-III band) groups, respectively. Excessive exposure of chlorine (i.e. $500 \mathrm{mg} \mathrm{L}^{-1}, 2,000 \mathrm{mg} \mathrm{L}^{-1}$ ) led in the weakening and destruction of the hydrogen bonds of $\mathrm{C}=\mathrm{O}$ groups, causing a shift of the band at $1,667 \mathrm{~cm}^{-1}$ to a higher wavelength (Kang et al., 2007a). In addition, the reduction of the amine groups (N-H) due to formation of chlorine amides $\left(\mathrm{N}-\mathrm{Cl}\right.$ ) lowered the band at $1,542 \mathrm{~cm}^{-1}$ (Figure $2 \mathrm{~b}-\mathrm{d}$ ). Other studies reported also a decrease in the intensity of the band at 3,330-3,060 $\mathrm{cm}^{-1}$, that corresponds to the Amide-I band (Antony et al., 2010). Although the results of these study were comparable to the 
one available in literature (Antony et al., 2010; Kang et al., 2007a), a small additional peak at $1,060 \mathrm{~cm}^{-1}$ was also found in this study on all membranes chlorinated with 500 and 2,000 $\mathrm{mg} \mathrm{L}^{-1}$ (Figure 2). The reason is not fully understood and is subject for further investigations.

\section{[TABLE 3]}

\section{[FIGURE 2]}

\subsubsection{Contact angle measurement}

The hydrophobic behaviour of the membranes can be determined by the measurement of the contact angle between the membrane surface and air/water interface. Changes in contact angle due to exposure to hypochlorite are presented in Figure 3. Buch et al. (Buch et al., 2008) reported that membrane chlorination increases the hydrophobic behaviour of polyamide membranes because of $\mathrm{N}$-chlorination and thus, the ability for water to form hydrogen bonds with the membrane polymer was reduced due to the absence of a hydrogen-bonding proton. Consequently, N-chlorination would decrease the ability of the water to penetrate into the membrane, resulting in an increase in the hydrophobic properties (Buch et al., 2008). However, in contrast to the results reported by Buch et al. (Buch et al., 2008), Kwon and Leckie (Kwon and Leckie, 2006) have also reported a decrease in the membrane contact angle due to chlorine exposure. This phenomenon was explained with unbalanced dipole moments on the membrane surface (Kwon and Leckie, 2006). In the current study, both an increase and decrease in the contact angle could be observed (Figure 3). It is noteworthy that the degradation with $100 \mathrm{mg} \mathrm{L}^{-1}$ hypochlorite led to the largest increase in the hydrophobic property, while 2,000 $\mathrm{mg} \mathrm{L}^{-1}$ hypochlorite appeared to show the tendency to decrease hydrophobicity. Results from Figure 3 suggest that the two mechanisms underlying the influence of chlorination on membrane hydrophobicity - N-chlorination in solutions with low chlorine concentrations and the presence of unbalanced dipole moments in solutions with high chlorine concentrations - can both occur.

\section{[FIGURE 3]}

\subsubsection{Surface roughness}

Conformational rearrangement of polyamide chains due to chlorination can result in changes in the membrane surface roughness. As shown in Figure 4, considerable decrease in the membrane surface roughness measured by AFM analysis could be observed after hypochlorite treatment. Previous studies examining the mechanisms of chlorine attack on polyamide membranes have suggested that $\mathrm{N}$-chlorination and concomitant ring-chlorination reactions could disrupt the intermolecular hydrogen bonds leading to rearrangement of polymeric chains and transformation 
from crystalline regions to an amorphous state (Kwon et al., 2008; Soice et al., 2003). Such a transformation could result in either a decrease or an increase in membrane surface roughness depending on the actual chemical composition and initial surface morphology of the membranes (Kwon et al., 2006). While further study is required to explain the three different trends observed here, changes in membrane surface morphology are likely be influenced by various factors including thickness and actual chemical composition of the polyamide skin layers.

\section{[FIGURE 4]}

\subsection{Membrane rejection}

\subsubsection{Effects of hypochlorite exposure on the rejection of inorganic salts}

Figure 5 shows changes in salt rejection (measured by conductivity) by the virgin and hypochlorite degraded membranes at different hypochlorite concentrations. Salt rejection values of the membranes in virgin condition after 25 hours of filtration are in good agreement with data specified by the manufacturers and in the order of ESPA2 (99\%) > BW30 (98\%) > NF90 (94\%) > NF270 (26\%). It is interesting to note a small but clearly discernible increase of salt rejection by all membranes that have been exposed to $100 \mathrm{mg} \mathrm{L}^{-1}$ hypochlorite, and finally a decrease for all membranes, which were treated with $2,000 \mathrm{mg} \mathrm{L}^{-1}$ of hypochlorite. In fact, when 2,000 $\mathrm{mg} \mathrm{L}^{-1}$ of hypochlorite was used to degrade the membranes, salt rejection was consistently lower than that by the virgin membranes (Figure 5). The increasing of the salt rejection due to slightly chlorinated membranes can be explained with the "tightening up effect” previously proposed by Kang et al. (Kang et al., 2007b). In contrast, the decrease in salt rejection can be explained with rearranged polyamide chains, which leads to a more open structure in the membranes. It is also noteworthy that similar to the results reported by Kwon and Leckie (Kwon and Leckie, 2006), a small decrease in the membrane permeability was observed when exposed to $100 \mathrm{mg} \mathrm{L}^{-1}$ of hypochlorite (data not shown). In general, the phenomena of increasing and decreasing in rejection due to chlorine influence were higher for the NF membranes compared to the RO membranes. This is possibly due to the more open structure of the NF membranes.

\section{[FIGURE 5]}

\subsubsection{Effects of hypochlorite exposure on the rejection of trace organic contaminants}

To examine the effects of hypochlorite exposure on the membrane separation capacity with regard to trace organic contaminants, rejection values of the two selected trace organic contaminants, namely sulfamethoxazole and carbamazepine, were evaluated under virgin membrane conditions and after treatment with various hypochlorite concentrations. At $\mathrm{pH}$ of the filtration experiments in 
this study (pH 8) sulfamethoxazole is a negatively charged compound while carbamazepine exists as a neutral species (Table 1) (Nghiem et al., 2005). Because the membranes are also negatively charged at pH 8 (Table 2), charge repulsion between the negatively charged sulfamethoxazole and the membrane surface leads to a high rejection of this compound by all membranes selected in this study (Figure 6). Under virgin condition, sulfamethoxazole rejection by the loose NF270 was $92 \%$. In good agreement with the above observation regarding the effects of chlorination on salt rejection, a small increase in sulfamethoxazole rejection was observed by all four membranes after they had been exposed to a low concentration $\left(100 \mathrm{mg} \mathrm{L}^{-1}\right)$ of hypochlorite. Once again, such a small increase in rejection of sulfamethoxazole by slightly chlorinated NF/RO membranes can be explained by the "tightening up effect” previously proposed in the literature (Kang et al., 2007b). It is also noteworthy that exposure to hypochlorite can lead to a significant increase in the membrane charge density (Simon et al., 2009), which may ultimately result in an enhanced charge repulsion and subsequently an increase in rejection of negatively charged solutes.

\section{[FIGURE 6]}

The rejection of sulfamethoxazole by the NF270 and BW30 is consistently higher than that of carbamazepine, which is a neutral compound (Figure 7). It is evident that the impact of hypochlorite exposure was more significant for the neutral carbamazepine than that of sulfamethoxazole. Furthermore, the loose NF270 membrane appears to be more sensitive to chlorination than that of the reverse osmosis BW30. Once again, an increase in rejection possibly due to the "tightening up effect" can be observed when the membranes were exposed to a low concentration of hypochlorite. Similarly, the detrimental effect of chlorine degradation when the solution strength of hypochlorite was 2,000 $\mathrm{mg} \mathrm{L}^{-1}$ was also obvious for the NF270 membrane. It is interesting to note that the BW30 also showed a small but clearly discernible decrease in the rejection of carbamazepine after exposure to 2,000 $\mathrm{mg} \mathrm{L}^{-1}$ of hypochlorite. Such degradation effect was absent for the negatively charged sulfamethoxazole (Figure 7).

\section{[FIGURE 7]}

\section{Conclusion}

This research investigated the changes in membrane properties due to hypochlorite exposure, and the subsequent alteration in separation capacity of inorganic salt and two selected trace organic contaminants - namely sulfamethoxazole and carbamazepine. SEM-EDS analysis demonstrated the presence of chlorine within the membrane polymeric matrix after being exposed to hypochlorite. In addition, membrane chlorination lowered and shifted the bands at 1,667 and 1,542 
$\mathrm{cm}^{-1}$ (Amide-II and III) likely due to the destruction of hydrogen bonds of $\mathrm{C}=\mathrm{O}$ and $\mathrm{N}-\mathrm{H}$ groups. The membrane surface became smoother in general as a result of hypochlorite exposure. Such changes in the membrane roughness are likely due to the rearrangement of polyamide chains. Exposing the membrane to a hypochlorite concentration of $100 \mathrm{mg} \mathrm{L}^{-1}$ resulted in an increase in the membrane hydrophobicity possibly due to N-chlorination, which reduced the number of hydrogen bonding sites. In contrast, high hypochlorite concentrations $\left(2,000 \mathrm{mg} \mathrm{L}^{-1}\right)$ at $\mathrm{pH} 7$ rendered the membranes more hydrophilic. This was probably because of unbalanced dipole moments and/or the dissolution of the coating layer. These changes in the membrane properties led to clearly discernible changes in the rejection of inorganic salt as well as trace organic contaminants. A small increase in rejection was consistently observed with all four membranes selected in this study after being exposed to a low concentration of hypochlorite (100 mg L $\left.{ }^{-1}\right)$. In contrast, higher concentration of hypochlorite $\left(2,000 \mathrm{mg} \mathrm{L}^{-1}\right)$ could be detrimental to the membrane separation capacity. Membranes with severe chlorine impact showed a considerable decrease in rejection over filtration time possibly due to rearrangement of the polyamide chains under the influence of chlorine degradation and filtration pressure. Results also indicate that the loose nanofiltration membrane NF270 is more sensitive to chlorine exposure than the other tight NF and the two RO membranes selected in this study. Similarly, the impact of hypochlorite exposure (both positive and negative) on rejection is more significant for the neutral carbamazepine compound than the negatively charged sulfamethoxazole.

\section{Acknowledgments}

This work was supported by the Australian Research Council Discovery Project "Optimising nanofiltration and reverse osmosis filtration processes for water recycling: effects of fouling and chemical cleaning on trace contaminant removal” (DP0985389). Dow FilmTec (Minneapolis, MN) and Hydranautics (Oceanside, CA) are thanked for the provision of membrane samples. Laboratory support from Adam Kiss and Hakeem Al-Turki is also greatly appreciated. 


\section{References}

Agenson, K.O., Urase, T. 2007. Change in membrane performance due to organic fouling in nanofiltration (NF)/reverse osmosis (RO) applications. Sep. Purif. Technol., 55, 147.

Antony, A., Fudianto, R., Cox, S., Leslie, G. 2010. Assessing the oxidative degradation of polyamide reverse osmosis membrane-Accelerated ageing with hypochlorite exposure. $J$. Membr. Sci., 347, 159-164.

Bartels, C.R., Wilf, M., Andes, K., Iong, J. 2005. Design considerations for wastewater treatment by reverse osmosis. Water Sci. Technol., 51, 473-482.

Bellona, C., Drewes, J.E. 2005. The role of membrane surface charge and solute physico-chemical properties in the rejection of organic acids by NF membranes. J. Membr. Sci., 249, 227234.

Bellona, C., Drewes, J.E., Xu, P., Amy, G. 2004. Factors affecting the rejection of organic solutes during NF/RO treatment - a literature review. Water Res., 38, 2795-2809.

Buch, P.R., Jagan Mohan, D., Reddy, A.V.R. 2008. Preparation, characterization and chlorine stability of aromatic-cycloaliphatic polyamide thin film composite membranes. J. Membr. Sci., 309, 36.

Bui, N.-N., Lind, M.L., Hoek, E.M.V., McCutcheon, J.R. 2011. Electrospun nanofiber supported thin film composite membranes for engineered osmosis. J. Membr. Sci., 385-386, 10-19.

Chang, K.-S., Huang, Y.-H., Lee, K.-R., Tung, K.-L. 2010. Free volume and polymeric structure analyses of aromatic polyamide membranes: A molecular simulation and experimental study. J. Membr. Sci., 354, 93-100.

da Silva, M.K., Tessaro, I.C., Wada, K. 2006. Investigation of oxidative degradation of polyamide reverse osmosis membranes by monochloramine solutions. J. Membr. Sci., 282, 375-382.

Freger, V., Gilron, J., Belfer, S. 2002. TFC polyamide membranes modified by grafting of hydrophilic polymers: an FT-IR/AFM/TEM study. J. Membr. Sci., 209, 283-292.

Fujioka, T., Khan, S.J., Poussade, Y., Drewes, J.E., Nghiem, L.D. 2012. N-nitrosamine removal by reverse osmosis for indirect potable water reuse - A critical review based on observations from laboratory-, pilot- and full-scale studies. Sep. Purif. Technol., 98, 503515.

Glater, J., Hong, S.K., Elimelech, M. 1994. The search for a chlorine-resistant reverse osmosis membrane. Desalination, 95, 325-345.

Kang, G., Gao, C., Chen, W., Jie, X., Cao, Y., Yuan, Q. 2007a. Study on hypochlorite degradation of aromatic polyamide reverse osmosis membrane. J. Membr. Sci., 300, 165-171.

Kang, G.D., Gao, C.J., Chen, W.D., Jie, X.M., Cao, Y.M., Yuan, Q. 2007b. Study on hypochlorite degradation of aromatic polyamide reverse osmosis membrane. J. Membr. Sci., 300, 165171.

Kwon, Y.N., Leckie, J.O. 2006. Hypochlorite degradation of crosslinked polyamide membranes I. Changes in chemical/morphological properties. J. Membr. Sci., 283, 21-26.

Kwon, Y.N., Tang, C.Y., Leckie, J.O. 2008. Change of chemical composition and hydrogen bonding behavior due to chlorination of crosslinked polyamide membranes. J. Appl. Polym. Sci., 108, 2061-2066. 
Kwon, Y.N., Tang, C.Y., Leckie, J.O. 2006. Change of membrane performance due to chlorination of crosslinked polyamide membranes. J. Appl. Polym. Sci., 102, 5895-5902.

López-Muñoz, M.J., Sotto, A., Arsuaga, J.M., Van der Bruggen, B. 2009. Influence of membrane, solute and solution properties on the retention of phenolic compounds in aqueous solution by nanofiltration membranes. Sep. Purif. Technol., 66, 194-201.

Nghiem, L.D., Coleman, P.J. 2008. NF/RO filtration of the hydrophobic ionogenic compound triclosan: Transport mechanisms and the influence of membrane fouling. Sep. Purif. Technol., 62, 709-716.

Nghiem, L.D., Espendiller, C., Braun, G. 2008a. Influence of organic and colloidal fouling on the removal of sulphamethoxazole by nanofiltration membranes. Water Sci. Technol., 58, 163169.

Nghiem, L.D., Schafer, A.I., Elimelech, M. 2006. Role of electrostatic interactions in the retention of pharmaceutically active contaminants by a loose nanofiltration membrane. J. Membr. Sci., 286, 52.

Nghiem, L.D., Schäfer, A.I., Elimelech, M. 2005. Pharmaceutical Retention Mechanisms by Nanofiltration Membranes. Environ. Sci. Technol., 39, 7698-7705.

Nghiem, L.D., Schäfer, A.I., Elimelech, M. 2004. Removal of Natural Hormones by Nanofiltration Membranes: Measurement, Modeling, and Mechanisms. Environ. Sci. Technol., 38, 1888-1896.

Nghiem, L.D., Vogel, D., Khan, S. 2008b. Characterising humic acid fouling of nanofiltration membranes using bisphenol A as a molecular indicator. Water Res., 42, 4049.

Semião, A.J.C., Schäfer, A.I. 2013. Removal of adsorbing estrogenic micropollutants by nanofiltration membranes. Part A-Experimental evidence. J. Membr. Sci., 431, 244-256.

Shannon, M.A., Bohn, P.W., Elimelech, M., Georgiadis, J.G., Marinas, B.J., Mayes, A.M. 2008. Science and technology for water purification in the coming decades. Nature, 452, 301310.

Simon, A., Nghiem, L.D., Le-Clech, P., Khan, S.J., Drewes, J.E. 2009. Effects of membrane degradation on the removal of pharmaceutically active compounds (PhACs) by NF/RO filtration processes. J. Membr. Sci., 340, 16-25.

Simon, A., Price, W.E., Nghiem, L.D. 2013. Impact of chemical cleaning on the nanofiltration of pharmaceutically active compounds (PhACs): The role of cleaning temperature. J. Taiwan Inst. Chem. E., (In press).

Soice, N.P., Greenberg, A.R., Krantz, W.B., Norman, A.D. 2004. Studies of oxidative degradation in polyamide RO membrane barrier layers using pendant drop mechanical analysis. $J$. Membr. Sci., 243, 345-355.

Soice, N.P., Maladono, A.C., Takigawa, D.Y., Norman, A.D., Krantz, W.B., Greenberg, A.R. 2003. Oxidative degradation of polyamide reverse osmosis membranes: Studies of molecular model compounds and selected membranes. J. Appl. Polym. Sci., 90, 1173-1184.

Tang, C.Y., Kwon, Y.-N., Leckie, J.O. 2009. Effect of membrane chemistry and coating layer on physiochemical properties of thin film composite polyamide RO and NF membranes: I. FTIR and XPS characterization of polyamide and coating layer chemistry. Desalination, 242, 149-167.

Urase, T., Sato, K. 2007. The effect of deterioration of nanofiltration membrane on retention of pharmaceuticals. Desalination, 202, 385. 
Van der Bruggen, B., Mänttäri, M., Nyström, M. 2008. Drawbacks of applying nanofiltration and how to avoid them: A review. Sep. Purif. Technol., 63, 251.

Van der Bruggen, B., Verliefde, A., Braeken, L., Cornelissen, E.R., Moons, K., Verberk, J., van Dijk, H.J.C., Amy, G. 2006. Assessment of a semi-quantitative method for estimation of the rejection of organic compounds in aqueous solution in nanofiltration. J. Chem. Technol. Biotechnol., 81, 1166-1176.

Verliefde, A.R.D., Cornelissen, E.R., Heijman, S.G.J., Petrinic, I., Luxbacher, T., Amy, G.L., Van der Bruggen, B., van Dijk, J.C. 2009. Influence of membrane fouling by (pretreated) surface water on rejection of pharmaceutically active compounds (PhACs) by nanofiltration membranes. J. Membr. Sci., 330, 90.

Wilf, M., Alt, S. 2000. Application of low fouling RO membrane elements for reclamation of municipal wastewater. Desalination, 132, 11.

Wintgens, T., Melin, T., Schäfer, A., Khan, S., Muston, M., Bixio, D., Thoeye, C. 2005. The role of membrane processes in municipal wastewater reclamation and reuse. Desalination, 178, 1 .

Xu, P., Drewes, J.E., Kim, T.-U., Bellona, C., Amy, G. 2006. Effect of membrane fouling on transport of organic contaminants in NF/RO membrane applications. J. Membr. Sci., 279, 165. 


\section{List of captions}

Figure 1: Scanning electron microscopic images of the virgin NF270, NF90, BW30 and ESPA2 membranes.

Figure 2: FTIR spectra before and after being exposed to 100,500 , and 2,000 $\mathrm{mg} / \mathrm{L}$ of sodium hypochlorite at a pH of 7 (denoted as D100, D500, and D2000, respectively).

Figure 3: Change in the membrane hydrophobicity after being exposed to 100, 500, and 2,000 mg/L of sodium hypochlorite (denoted as D100, D500, and D2000, respectively) at pH 7.

Figure 4: Change in the membrane average surface roughness after being exposed to 100, 500, and 2,000 mg/L of sodium hypochlorite (denoted as D100, D500, and D2000, respectively) at pH 7 .

Figure 5: Conductivity rejection before and after being exposed to 100, 500, and 2,000 mg/L of sodium hypochlorite at a pH of 7 (denoted as D100, D500, and D2000, respectively). Feed solution contained $1 \mathrm{mM} \mathrm{CaCl}_{2}, 20 \mathrm{mM} \mathrm{NaCl}$ and $1 \mathrm{mM} \mathrm{NaHCO}_{3}$ at $\mathrm{pH} 8$ (cross flow velocity $30.4 \mathrm{~cm} / \mathrm{s}$; temperature $=20 \pm 0.1^{\circ} \mathrm{C}$ ). Feed and permeate samples were collected after 25 hours of filtration. The applied pressure for the NF270 membrane was 5 bar and for all other membranes was 10 bar.

Figure 6: Sulfamethoxazole rejection as well as feed and permeate concentration by the virgin membranes and membranes after being exposed to $100 \mathrm{mg} / \mathrm{L}$ of sodium hypochlorite (denoted as D100) at pH 7. Feed solution contained $1 \mathrm{mM} \mathrm{CaCl}_{2}, 20 \mathrm{mM} \mathrm{NaCl}$ and $1 \mathrm{mM} \mathrm{NaHCO}$ at $\mathrm{pH} 8$ (cross flow velocity $30.4 \mathrm{~cm} / \mathrm{s}$; temperature $=20 \pm 0.1{ }^{\circ} \mathrm{C}$ ). Feed and permeate samples were collected after 25 hours of filtration.

Figure 7: (A) - Sulfamethoxazole and (B) - Carbamazepine rejection before and after being exposed to 100, 500, and 2,000 mg/L of sodium hypochlorite at a pH of 7 (denoted as D100, D500, and D2000, respectively). Feed solution contained $1 \mathrm{mM} \mathrm{CaCl}_{2}, 20 \mathrm{mM} \mathrm{NaCl}$ and $1 \mathrm{mM}$ $\mathrm{NaHCO}_{3}$ at $\mathrm{pH} 8$ (cross flow velocity $30.4 \mathrm{~cm} / \mathrm{s}$; temperature $=20 \pm 0.1{ }^{\circ} \mathrm{C}$ ). Feed and permeate samples were collected after 25 hours of filtration. 


\section{List of Tables}

Table 1. Physicochemical properties of the selected trace organic compounds.

\begin{tabular}{|l|c|c|}
\hline Trace organic & Sulfamethoxazole \\
\hline Molecular structure & 253.3 & 236.3 \\
\hline Molecular weight (g/mol) & 0.89 & 2.67 \\
\hline Log Kow & 16 & -0.22 \\
\hline Solubility (g/L) at $25^{\circ} \mathrm{C}$ and $\mathrm{pH} 8$ & 1.39 \& 5.81 & Neutral \\
\hline Dissociation constant $(\mathrm{pKa})$ & Negative & ( \\
\hline Charge at $\mathrm{pH} 8$ & &
\end{tabular}

Table 2. Properties of the selected NF and RO membranes.

\begin{tabular}{|l|c|c|c|c|}
\hline Membrane & $\begin{array}{c}\text { Permeability } \\
\left(\mathrm{L} \mathrm{m}^{2} \mathrm{~h}^{-1} \text { bar }^{-1}\right)\end{array}$ & $\begin{array}{c}\text { Average pore } \\
\text { diameter }^{\mathrm{b}}(\mathrm{nm})\end{array}$ & $\begin{array}{c}\text { NaCl } \\
\text { rejection (\%) }\end{array}$ & $\begin{array}{c}\text { Surface charge at } \\
\mathrm{pH} \mathrm{8}^{\mathrm{a}}\end{array}$ \\
\hline NF270 & 12.1 & 0.84 & 45.0 & Negative \\
\hline NF90 & 6.2 & 0.68 & 85.0 & Negative \\
\hline ESPA2 & 3.7 & na & 96.5 & Negative \\
\hline BW30 & 2.9 & na & 97.7 & Negative \\
\hline
\end{tabular}

na: not available.

a - Measured in this study (Feed solution contained $20 \mathrm{mM} \mathrm{NaCl}$ and $1 \mathrm{mM} \mathrm{CaCl}_{2}$ at $\mathrm{pH}$ 8).

The applied pressure for the NF270 membrane was 5 bar and for all other membranes was 10 bar.

b - Ref. (Nghiem et al., 2004) 
Table 3: Assignment of FTIR peaks

\begin{tabular}{|c|c|c|c|}
\hline Wavenumber $\left(\mathrm{cm}^{-1}\right)$ & FTIR peak assignment & Polymer & Reference \\
\hline 1663 & $\begin{array}{l}\mathrm{C}=\mathrm{O} \text { and/or C-N stretching and/or C- } \\
\mathrm{C}-\mathrm{N} \text { deformation vibration (amide I) }\end{array}$ & Polyamide & $\begin{array}{l}\text { (Bui et al., } \\
\text { 2011; Tang et } \\
\text { al., 2009) }\end{array}$ \\
\hline 1640 & $\begin{array}{l}\text { Polypiperazinamide } \\
\text { (amide I) }\end{array}$ & $\begin{array}{l}\text { Poly- } \\
\text { piperazinamide }\end{array}$ & $\begin{array}{l}\text { (Tang et al., } \\
\text { 2009) }\end{array}$ \\
\hline 1586 and 1488 & $\begin{array}{c}\text { Aromatic in-plane bend stretching } \\
\text { vibration }\end{array}$ & Polysulphone & $\begin{array}{l}\text { (Bui et al., } \\
\text { 2011; Freger et } \\
\text { al., 2002; Tang } \\
\text { et al., 2009) }\end{array}$ \\
\hline 1544 & C-N stretching (amide II) & Polyamide & $\begin{array}{l}\text { (Bui et al., } \\
\text { 2011; Tang et } \\
\text { al., 2009) }\end{array}$ \\
\hline 1329 and 1295 & Asymmetric SO2 stretching & Polysulphone & $\begin{array}{l}\text { (Bui et al., } \\
\text { 2011; Freger et } \\
\text { al., 2002) }\end{array}$ \\
\hline 1243 & Asymmetric C-O-C stretching & $\begin{array}{l}\text { Polyester, } \\
\text { Polysulphone }\end{array}$ & $\begin{array}{l}\text { (Bui et al., } \\
\text { 2011; Freger et } \\
\text { al., 2002; Tang } \\
\text { et al., 2009) }\end{array}$ \\
\hline 1151 & Symmetric SO2 stretching & $\begin{array}{l}\text { Polyester, } \\
\text { Polysulphone }\end{array}$ & $\begin{array}{l}\text { (Bui et al., } \\
\text { 2011; Freger et } \\
\text { al., 2002) }\end{array}$ \\
\hline 1106 & $\begin{array}{l}\text { Aliphatic C-C/aromatic hydrogen } \\
\text { bending/rocking }\end{array}$ & $\begin{array}{l}\text { Polyester, } \\
\text { Polysulphone }\end{array}$ & $\begin{array}{l}\text { (Bui et al., } \\
\text { 2011) }\end{array}$ \\
\hline$\sim 830$ & Para substituted phenyl groups & Polysulphone & $\begin{array}{c}\text { (Tang et al., } \\
\text { 2009) }\end{array}$ \\
\hline
\end{tabular}




\section{List of Figures}
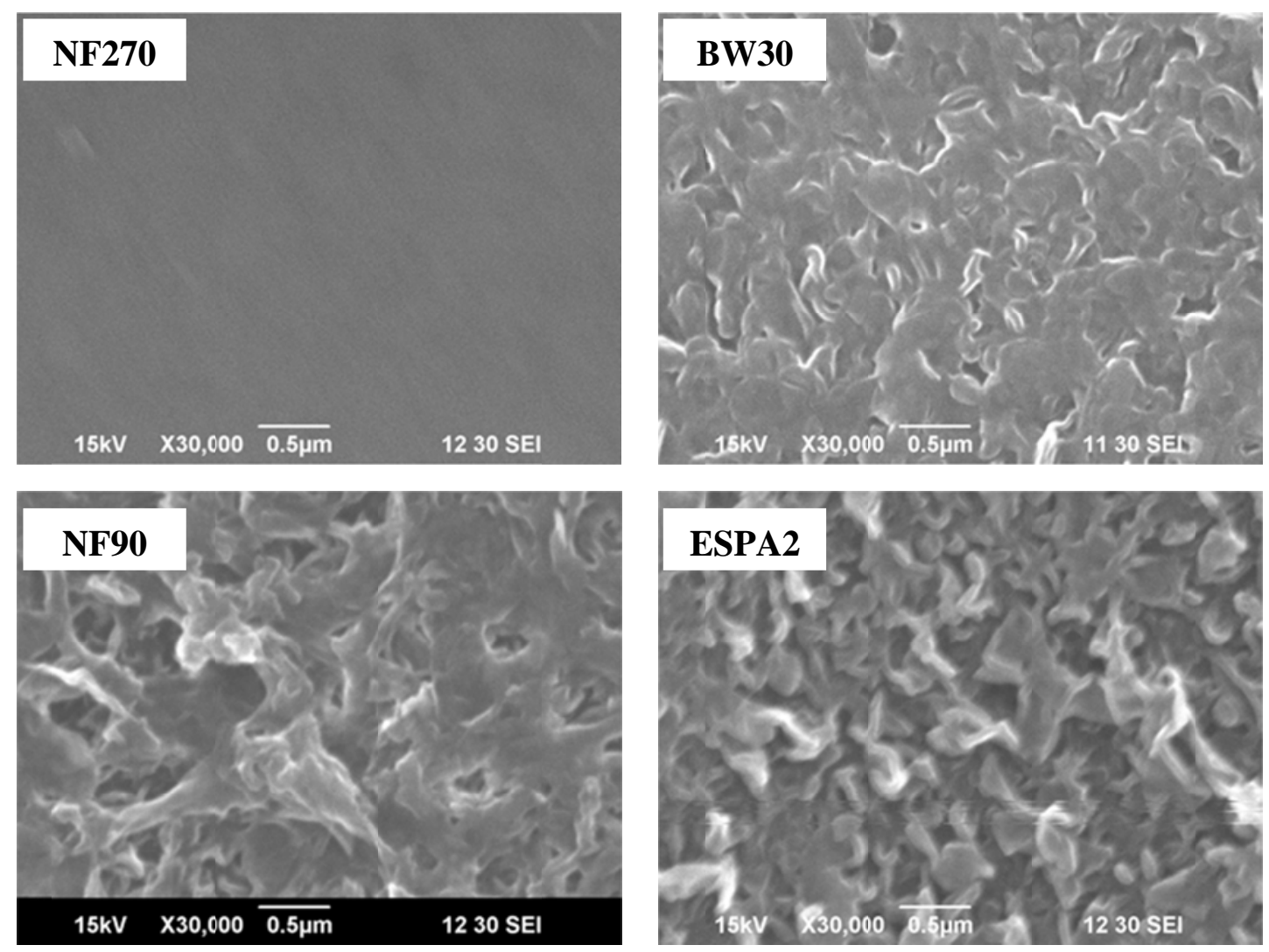

Figure 1 

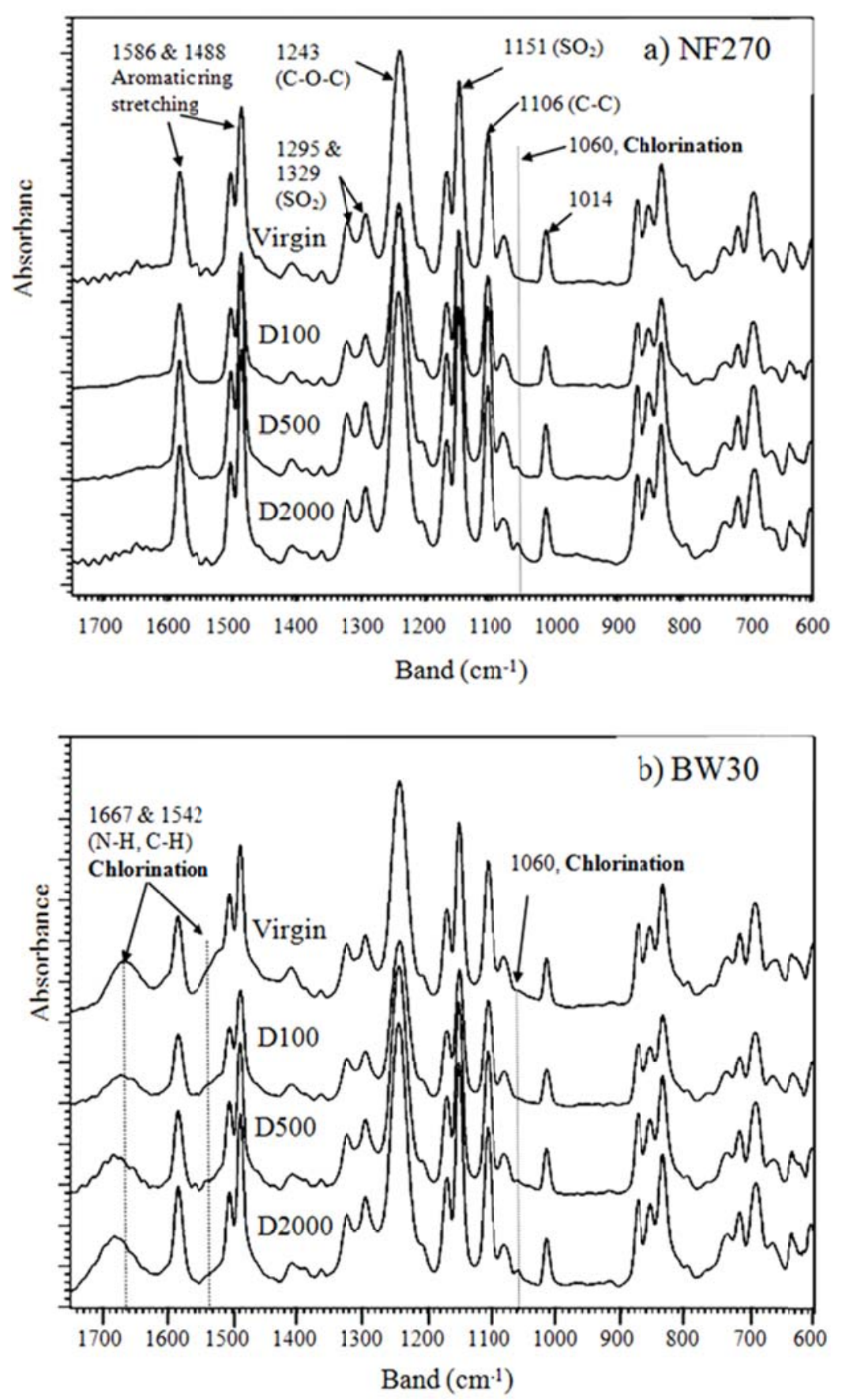

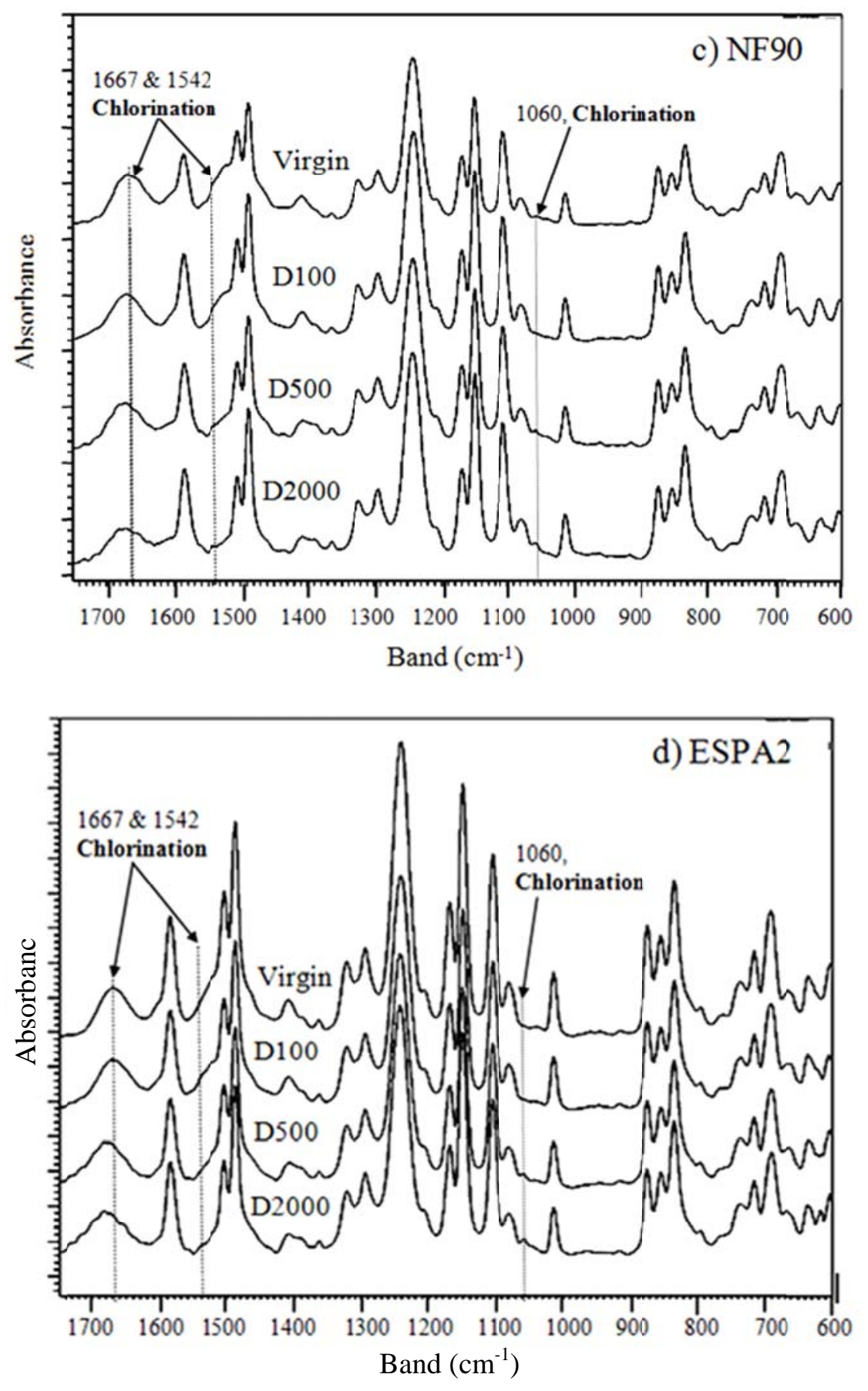

Figure 2 


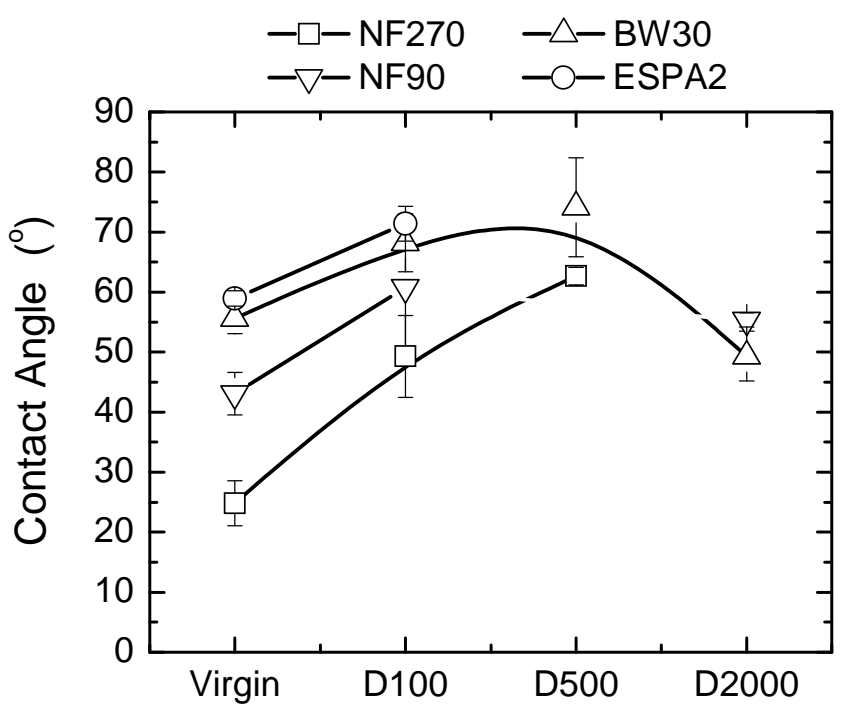

Figure 3 


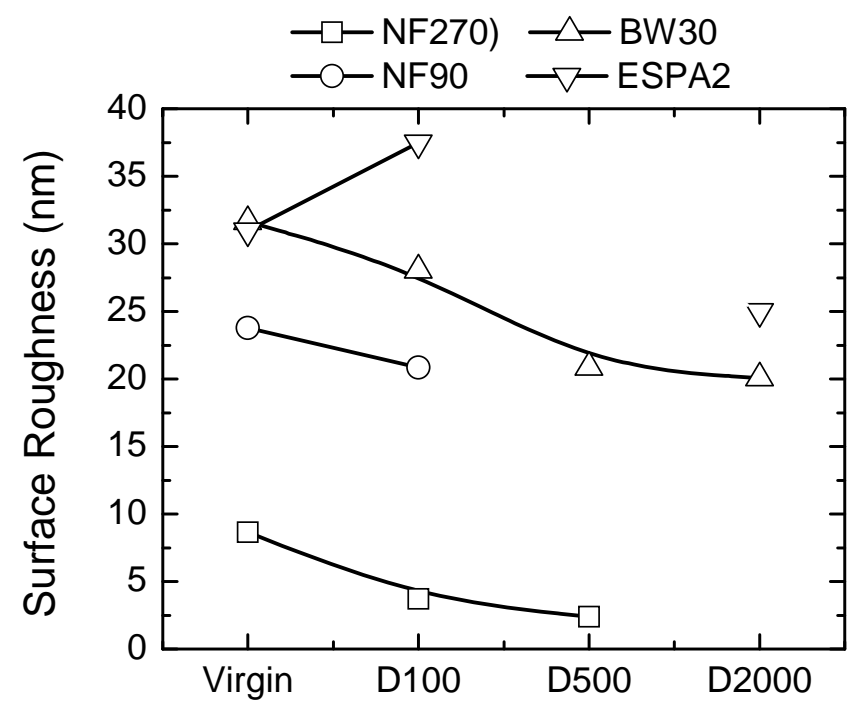

Figure 4 


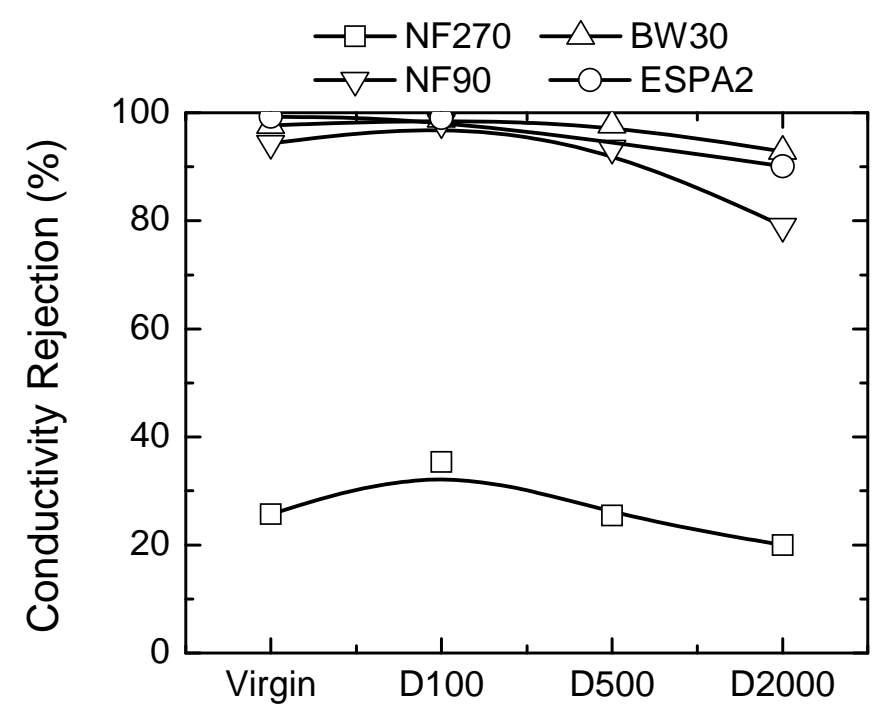

Figure 5 

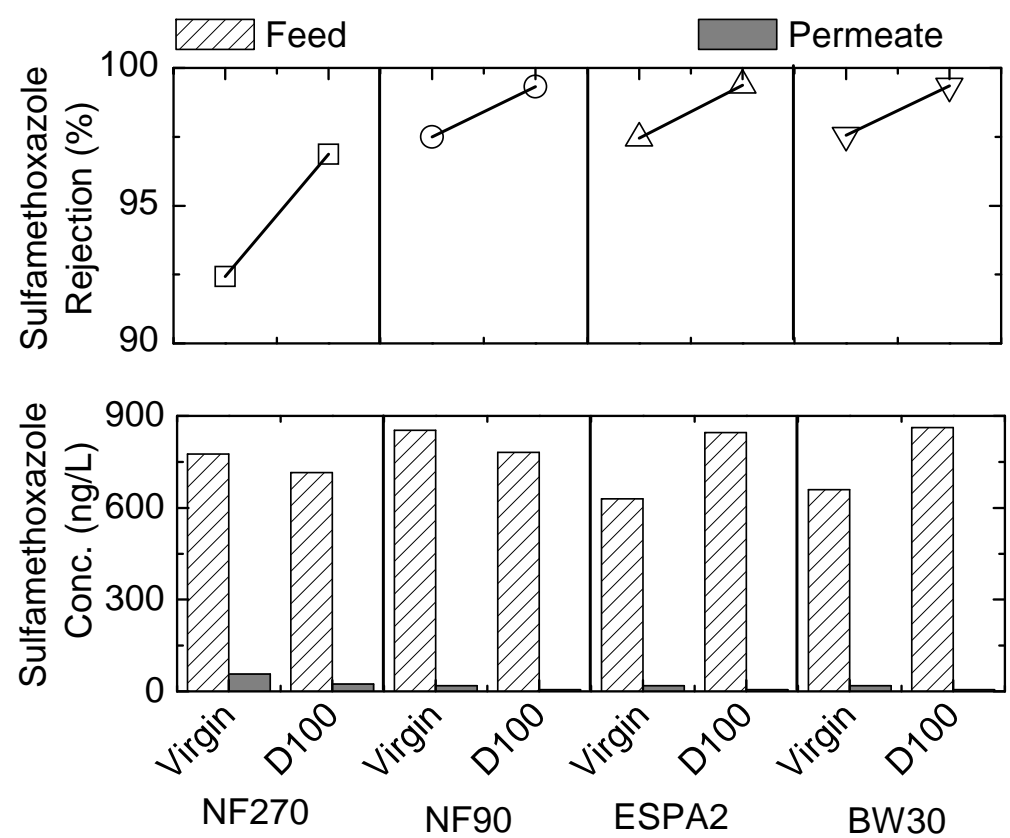

Figure 6 

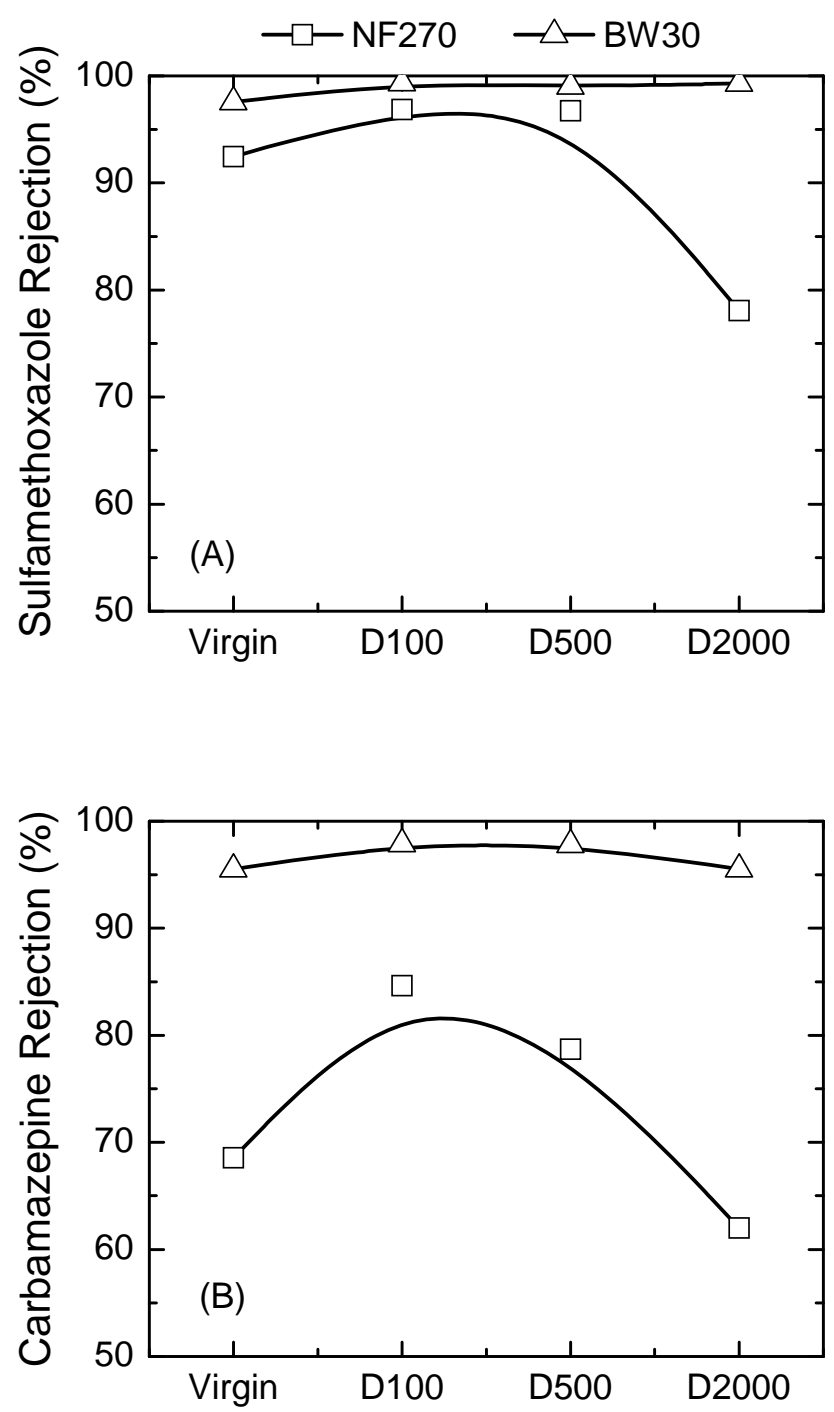

Figure 7 